\title{
Power quality of dual two-level inverter fed open end winding induction motor
}

\author{
Hayder Ali Mohamed, Hanan Mikhael D. Habbi
}

Electical Engineering Department, University of Baghdad, Iraq

\begin{tabular}{|c|c|}
\hline Article Info & ABSTRACT \\
\hline Article history: & This paper presents the minimization of the total harmonic distortion (THD) \\
\hline Received Aug 2, 2019 & $\begin{array}{l}\text { of the current signal for open-end winding induction motor by using dual } \\
\text { two-level inverter. In order to obtain a good value of THD, the space vector }\end{array}$ \\
\hline Revised Nov 3, 2019 & PWM has been used for switching the dual two-level inverter to improve the \\
\hline Accepted Nov 17, 2019 & $\begin{array}{l}\text { output voltage quality, gets a low common mode voltage, reduce the } \\
\text { execution time, and to save the memory capacity. The proposed scheme uses }\end{array}$ \\
\hline Keywords: & $\begin{array}{l}\text { two different DC voltage source with two two level inverter in order of } \\
\text { minimizing the number of components. As well as it is an important to utilize }\end{array}$ \\
\hline $\begin{array}{l}\text { Dual inverter } \\
\text { OEWIM }\end{array}$ & $\begin{array}{l}\text { the energy which increases the application of dual inverter in microgrids. All } \\
\text { simulation results are obtained using Matlab/Simulink. }\end{array}$ \\
\hline
\end{tabular}

Copyright $\odot 2020$ Institute of Advanced Engineering and Science. All rights reserved.

Corresponding Author:

Hayder Ali Mohamed,

Electrical Engineering Department,

University of Baghdad,

Al-Jadriya, Baghdad, Iraq.

Email: haider_ali23@yahoo.com

\section{INTRODUCTION}

3-phase AC induction motor are widely used in industry. It was designed to work under constant speed and need an extra device to change its speed.

An inverter fed motor drive system has been vastly utilize in industry applications, especially on the last decade when a various type of switches became available and could easily gotten. power losses (total conversion losses) of inverter should be considered. PWM losses are caused by harmonic distortion of the current and voltage waveform [1].

Harmonic distortions are the rate of ripple from a fundamental waveform. That can be happened due to variations in load impedance or nonlinear magnetizing current. By using converters AC is converted to DC or vice versa based on work requirement. Due to this process harmonics will be produced on the current waveform these harmonics will produce harmonic on voltage waveform. The lower order harmonics (LOH) have a strong impact on the fundamental waveform. the even harmonics are eliminated due to the symmetry of waveform along axes [2].

The output current of 3-phase inverter has a huge THD higher than 33\% [3]. THD should be minimized to be suitable with the permissible limits setting in most of IEEE harmonic limitation standards [4-5]. In addition to PWM, there are many other methods are used to reduce THD [6]. The multirate sampling technique is applied for a 3-level carrier SVPWM of IM drive in order to reduce the torque ripple. It employed multirate sampling times for data capturing, control and estimation of flux, torque and speed signals. Whilst the other methods have been used the multilevel inverter which get lower harmonic distortion than two level inverter, but the switching losses is increased due to the increase of number of switching as well as the number of DC flying capacitor and clamping diodes are increased. To solve these problems, the dual inverter (two two-level inverter) [7-8] is implemented instead of multilevel inverter. This Dual inverter 
improves the problems of multilevel inverter, such as it does not require the neutral point clamping diodes and has a simple power circuit compared to the conventional three-level inverter [9-12]. It can be also observed that the two two-level inverter was derived from 3-level cascade H-bridge inverter, in both states it is utilized to minimize the number of required components [13]. However, the proposed scheme uses two different DC voltage source with two two level inverter besides that the number of components are less. As well as it is an important to utilize the energy which increases the application of dual inverter in microgrids due to its flexibility and system stability.

\section{RESEARCH METHOD}

\subsection{Three Phase Inverters}

The inverters are used to convert the DC voltage into AC voltage with controlled voltage and frequency. The waveform of the output voltage depends on the switching states of the six switches. Many applications of inverters face three major requirements and limitations. The harmonic contents, the switching frequency, and the best utilization of dc link voltage. In general, drive systems with low harmonic contents are better than that with high harmonic contents. High switching frequency usually improves the quality of the motor currents and consequently the whole performance of the drive system. However, high switching frequency leads to more switching losses in the inverter switches. Also, high switching frequency is limited by the switching capability and dead time of the switches [14]. The best utilization of the de link voltage depends on the applied technique of switching. A three phase two-level inverters voltage source inverter (VSI) configuration is shown in Figure1.

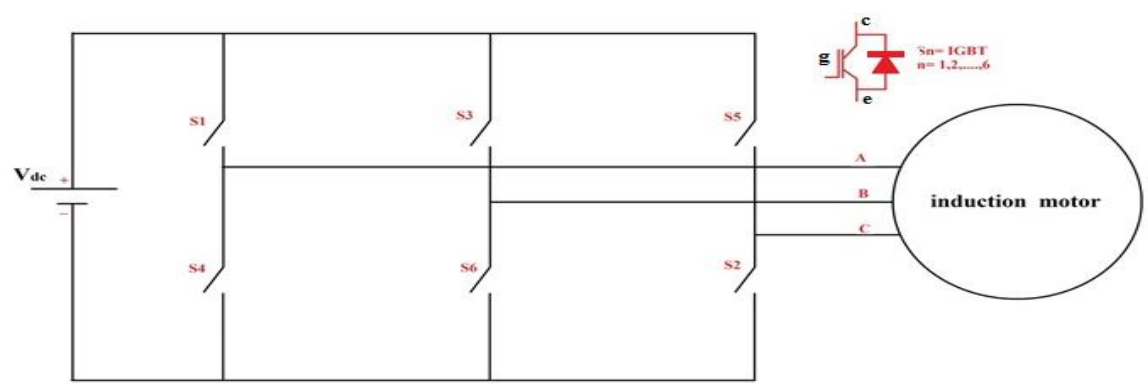

Figure 1. Three phase inverter configuration

\subsection{Dual Two-Level Inverter Fed Open-End Induction Motor}

Dual two-level inverter is a type of multilevel inverters. The topology of this inverter, as shown in Figure 2, is implemented by cascading two standard 3-phase inverters with a six-wire open-end load in between. It is equivalent to a 3-level 3-phase converter which will require three insulated sources if it is implemented as cascade $\mathrm{H}$-bridge.

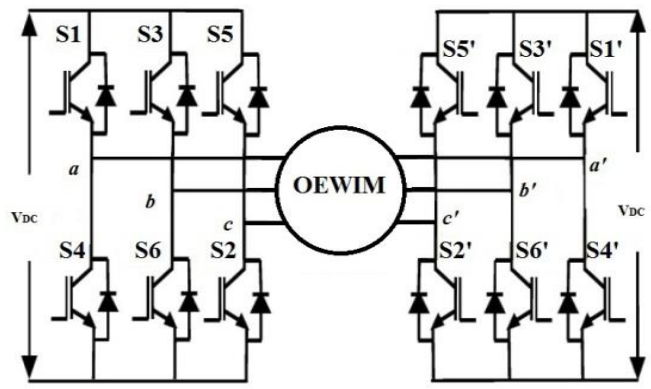

Figure 2. Dual Two-Level Inverter fed open-end winding induction motor with deferent DC source 
In this way, the required insulated sources are only two. Moreover, the converter is composed by wide commercialized and very reliable parts which make its implementation quite easy. It is well suited for automotive applications in which splitting the batteries bank is possible.

Dual two-level inverter consists of two standard 3-phase 2-level inverters with AC sides connected to the same 3-phase open-end 6-wire induction motor and the DC sides connected to two different voltage sources. It could be said that the dual 2-level inverter is a derivation of the 3-level cascade H-bridge like standard 3-phase inverter is for the single-phase converter: in both cases the strong bond among the phases is exploited to reduce the number of required components. Moreover, in Figure 3 two topologies exploiting one single source are shown. In Figure 3 the series configuration is obtained splitting the single source through the two capacitors feeding the inverters. Similarly, the parallel connection in Figure 3(b) has DC busses parallel connected to the same source.
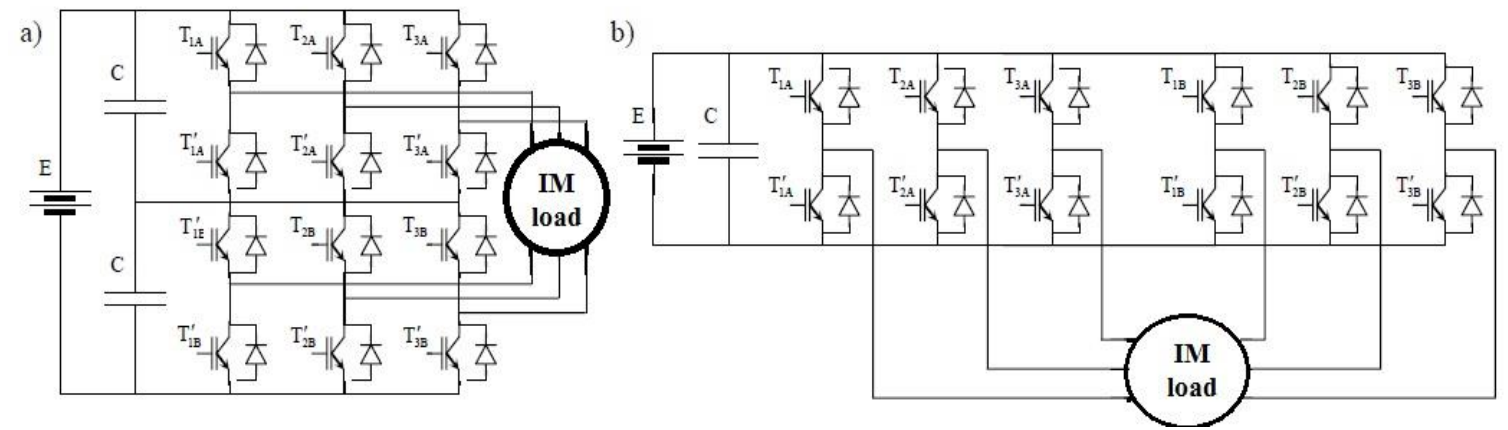

Figure 3. Dual 2-level inverter with one source. (a) Series configuration; (b) Parallel configuration

Independently of the configuration, this converter is implemented using two standard 3-phase inverters. The advantage of this choice is the great availability and the high reliability of the components because they are standards wide commercialized.

\subsection{Space Vector Modulation}

Space vector pulse-width modulation (SVPWM) is the most important PWM technique in motor drives because of excellent steady-state and dynamic performances.

In SVM technique, the combined effect of three phases is considered as one vector [15-16].

\subsection{Realization of SVM}

Realization of SVM involves

Step 1: Determination of Vd, Vq, Vref and angle $(\theta)$

Step 2: Determination of time duration To, Ta, and Tb

Step 3: Determination of the switching time of each transistor.

Firstly three phases (abc) are converted into two phases (dq) for simplicity, and its obtained using Park's transformation.

Here three phase voltages are defined as $V_{A}(t), V_{B}(t), V_{C}(t)$ can be represented uniquely by a rotating vector,

$$
\begin{aligned}
& \begin{array}{l}
V=V_{A}(t)+V_{B}(t) e^{j 2 \pi / 3}+V_{C}(t) e^{-J 2 \pi / 3} \\
V_{A}(t)=V_{m} \sin (\omega t) \\
V_{B}(t)=V_{m} \sin \left(\omega t-\frac{2}{3} \pi\right) \\
\text { where, } \left.\quad V_{C}(t)=V_{m} \sin \omega t+\frac{2}{3} \pi\right)
\end{array}
\end{aligned}
$$

Three phase frames are converted into two phase frames using any transformation technique. 
$\left[\begin{array}{l}V_{d} \\ V_{q}\end{array}\right]=\frac{2}{3}\left[\begin{array}{ccc}1 & -1 / 2 & -1 / 2 \\ 0 & \sqrt{3 / 2} & -\sqrt{3 / 2}\end{array}\right]\left[\begin{array}{c}v_{a n} \\ v_{b n} \\ v_{c n}\end{array}\right]$

The orthogonal two-phase system is given as ( $\mathrm{Vd}, \mathrm{Vq})$ :

$$
V_{d q}=V_{d}+j V_{q}
$$

$$
\begin{aligned}
V_{d q} & =\frac{2}{3}\left[\left(v_{a n}-\frac{1}{2} v_{b n}-\frac{1}{2} v_{c n}\right)+j\left(\frac{\sqrt{3}}{2} v_{b n}-\frac{\sqrt{3}}{2} v_{c n}\right)\right] \\
& =\frac{2}{3}\left[v_{c n}+\left(-\frac{1}{2}+j \frac{\sqrt{3}}{2}\right) v_{b n}+\left(-\frac{1}{2}-j \frac{\sqrt{3}}{2}\right) v_{c n}\right] \\
V_{c l q} & =\frac{2}{3}\left[v_{a n}+a v_{b n}+a^{2} v_{c n}\right]
\end{aligned}
$$

Where: $V_{d q}=$ reference voltage

$$
\begin{aligned}
& a=-\frac{1}{2}+j \frac{\sqrt{3}}{2}=e^{\frac{j 2 \pi}{3}}, \text { and } a^{2}=-\frac{1}{2}-j \frac{\sqrt{3}}{2}=e^{\frac{-^{j 2 \pi}}{3}} \\
& \left|V_{d q}\right|=\sqrt{\left(V_{d}\right)^{2}+\left(V_{q}\right)^{2}}
\end{aligned}
$$

$$
\theta=\tan ^{-1}\left(\frac{V_{q}}{V_{d}}\right)
$$

The angle between Vd and Vref (or Vdq) is calculated as: $\theta=2 \pi f . t$

In a three-phase system, the vector representation is achieved by the transformation given in Figure 4. The reference vector as a combination of adjacent vectors at sector 1 is shown in Figure 5.

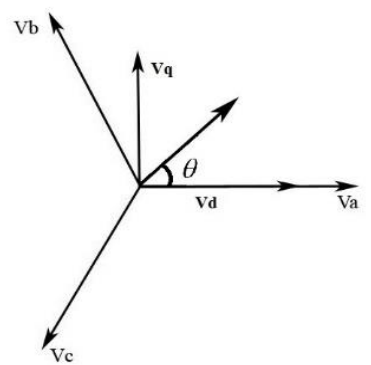

Figure 4. Relation between Stationary frames and dq frames

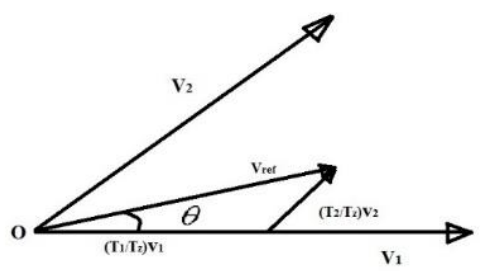

Figure 5. Reference vector as a combination of adjacent vectors at sector 1

Switching time duration at any sector is calculated as:

$$
\int_{0}^{T z} V_{r e f}=\int_{0}^{T a} V_{1} d t+\int_{T a}^{T a+T b} V_{2} d t+\int_{T a+T b}^{T z} V_{0} \text { or } V_{7}
$$




$$
\begin{aligned}
& T_{a}=T_{z} \cdot m i \cdot \sin \left(\frac{\pi}{3}-\theta\right) \\
& T_{b}=T_{z} \cdot m i \cdot \sin (\theta) \\
& T_{o}=T_{z}-T_{a}-T_{b}
\end{aligned}
$$

Where MI represent the value of modulation index

$$
m i=\frac{\sqrt{3} \cdot V_{r e f}}{V_{d c}}
$$

The modulation index (MI) and switching frequency (sampling frequency $f_{c}=\frac{1}{T_{s}}$ ) have impact on total distortion and losses.

The SVPWM sequence of pulses contains a useful base frequency and abundant high frequency harmonics. The set of high frequency harmonics are located nearby the carrier frequency and its multiples. Nowadays, 2-20 kHz switching frequencies are common [17]. The high switching frequency improves the harmonic spectrum by drifting the harmonics toward higher order, but this will increase the switching losses when conventional PWM is used.

The SVPWM technique satisfies the requirements for the minimization of switching frequency used with optimal switching losses [18].

The signal generation of space vector is compared to the triangular waveform to generate three PWM pulses to which NOT gates are given to get the other three pulses. The control signal of space vector PWM is given in Figure 6.

The carrier frequency (fc) used in our proposed system is $5 \mathrm{KHz}$, but in Figure 6 the user fc is 1 $\mathrm{KHz}$ to clarify how to compare the SVM signal with the carrier signal to get pulses. It's clear that in SVM there are only eight possible switching combinations for a three-phase inverter and those patterns are briefed as shown in Table 1.

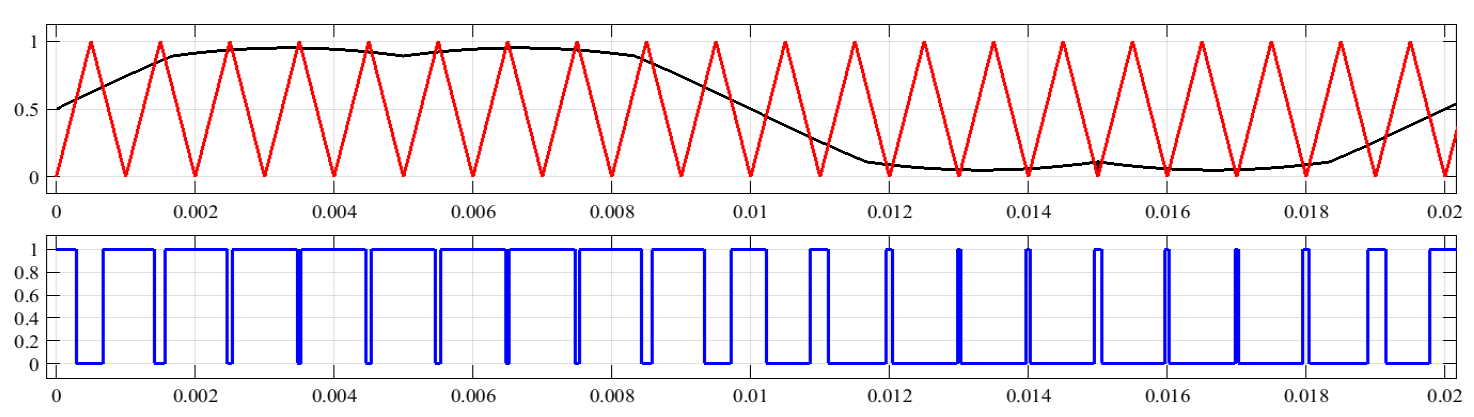

Figure 6. generating pulses in space vector PWM

Table 1. Switching Patterns and Voltage of SVM

\begin{tabular}{cccccccccc}
\hline Voltage in Vector & \multicolumn{3}{c}{ Switching Vectors } & \multicolumn{3}{c}{ Line-neutralvoltage } & \multicolumn{2}{c}{ Line-line voltage } \\
\hline V0 & 0 & 0 & 0 & 0 & 0 & 0 & 0 & 0 & 0 \\
V1 & 1 & 0 & 0 & $2 / 3$ & $-1 / 3$ & $-1 / 3$ & 1 & 0 & -1 \\
V2 & 1 & 1 & 0 & $1 / 3$ & $1 / 3$ & $-2 / 3$ & 0 & 1 \\
V3 & 0 & 1 & 0 & $-1 / 3$ & $2 / 3$ & $-1 / 3$ & -1 & 1 \\
V4 & 0 & 1 & 1 & $-2 / 3$ & $1 / 3$ & $1 / 3$ & -1 & 0 & 0 \\
V5 & 0 & 0 & 1 & $-1 / 3$ & $1 / 3$ & $2 / 3$ & 0 & -1 & 1 \\
V6 & 1 & 0 & 1 & $1 / 3$ & $-2 / 3$ & $1 / 3$ & 1 & -1 & 0 \\
V7 & 1 & 1 & 1 & 0 & 0 & 0 & 0 & 0 & 0 \\
\hline
\end{tabular}




\subsection{Block Diagram of SVPWM Fed Induction Motor Drive}

The proposed technique is to reduce the total harmonic distortion in to allowable value. The total system comprises of a SVM pulse generator, inverter circuit and an induction motor load.

Figure 7 illustrates the block diagram of a single inverter when connected to a load.

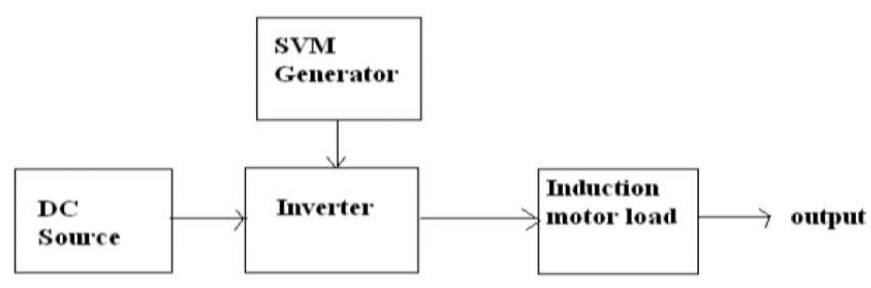

Figure 7. Block diagram of the system

The three-phase inverter has six power switches S1 to S6 and are controlled by switching variables aa', bb', cc' as shown in Figure 1. When an upper transistor is switched on, i.e., when a, b or c is 1 , the corresponding lower transistor is switched off, i.e., the corresponding $a^{\prime}, b^{\prime}$ or $c^{\prime}$ is 0 . Therefore, the on and off states of the upper transistors S1, S3 and S5 can be used to determine the output voltage. The output voltage is measured and is given to the SVM controller. The control circuit regulates the output voltage. The SVM treats the sinusoidal voltage as a constant amplitude vector rotating at constant frequency. SVPWM technique approximates the reference voltage Vref by a combination of the eight switching patterns (V0 to V7). Three-phase voltage vector is transformed into a vector in the stationary d-q coordinate frame. The vectors (V1 to V6) divide the plane into six sectors (each sector: 60 degrees). Vref is generated by two adjacent non-zero vectors and two zero vectors.

The combined space vector diagram of Dual-inverter fed open-end configuration is similar to a three-level NPC inverter with 19 distinct voltage vectors out of the total 27 switching states. Among these 19 voltage vectors 7 of them does not contribute any CMV across the machine phase windings as shown in Figure 8. The two inverters are modulated using SVPWM strategy such that CMV of both inverters are equal and CMV across machine windings is zero.

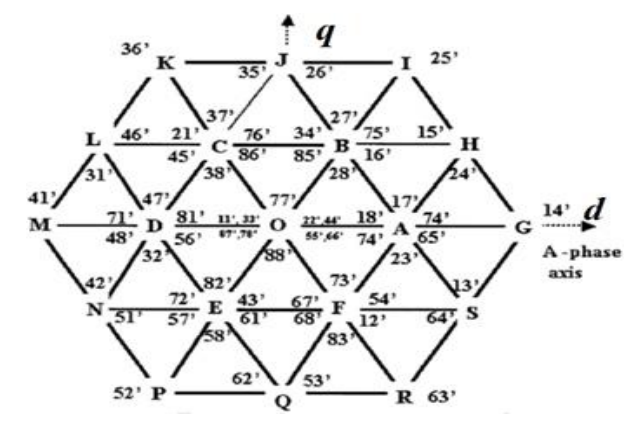

Figure 8. Combined Space vector diagram of Dual inverter

\subsection{Open end Winding Induction Motor}

Open-end winding induction machine is obtained by opening the neutral point of conventional star connected induction machine which results in six terminals instead of three and requires two standard twolevel inverter on either sides of the machine as shown in Figure 9. The pole voltages at the two sets of machine terminals are defined as the average of the pole voltages as:

$$
\left[\begin{array}{c}
V_{r o} \\
V_{y o} \\
V_{b o}
\end{array}\right]=\left(\frac{2}{3} * V_{d c}\right)\left[\begin{array}{l}
S_{r} \\
S_{y} \\
S_{b}
\end{array}\right]
$$




$$
\left[\begin{array}{c}
V_{r^{\prime} o^{\prime}} \\
V_{y^{\prime} o^{\prime}} \\
V_{b^{\prime} o^{\prime}}
\end{array}\right]=\left(\frac{1}{3} * V_{d c}\right)\left[\begin{array}{c}
S_{r}^{{ }^{\prime}} \\
S_{y}^{{ }^{\prime}} \\
S_{b}^{\prime}
\end{array}\right]
$$

$$
\left[\begin{array}{c}
\Delta \mathrm{V}_{\mathrm{rr}} \\
\Delta \mathrm{V}_{\mathrm{yy}} \\
\Delta \mathrm{V}_{\mathrm{bb}}
\end{array}\right]=\left[\begin{array}{c}
V_{r o}-V_{r^{\prime} o^{\prime}} \\
V_{y o}-V_{y^{\prime} o^{\prime}} \\
V_{b o}-V_{b^{\prime} o^{\prime}}
\end{array}\right]
$$

From the difference of phase voltages, the common-mode voltage can be written as (7) and phase voltages of OEWIM are given by (8).

$$
\begin{gathered}
V_{o o}^{\prime}=V_{o}=\left(\frac{1}{3}\right)\left(\Delta V_{r r^{\prime}}+\Delta V_{y y^{\prime}}+\Delta V_{b b^{\prime}}\right) \\
{\left[\begin{array}{c}
V_{r r^{\prime}} \\
V_{y y^{\prime}} \\
V_{b b^{\prime}}
\end{array}\right]=\frac{1}{3}\left[\begin{array}{ccc}
2 & -1 & -1 \\
-1 & 2 & -1 \\
-1 & -1 & 2
\end{array}\right]\left[\begin{array}{c}
\Delta V_{r r^{\prime}} \\
\Delta V_{y y^{\prime}} \\
\Delta V_{b b^{\prime}}
\end{array}\right] .}
\end{gathered}
$$

The conventional d-q model of a normal 3-phase induction motor is modified to compute the motor phase current of the open-end winding induction motor drive as shown in Figure 9. The inputs for this model are the PWM signals of the individual inverters and their DC link voltages. The pole voltages of the individual inverters are then computed. Subtracting the pole voltages of inverter-2 from those of inverter-1, the difference of pole voltages is obtained and supplied to the conventional d-q model of induction motor to compute motor phase currents. Inverter is modeled using the basic output voltage equations [19-20]. Also it is necessary to know in which sector the reference output lies in order to determine the switching time and sequence [21-22]. The angle of the reference vector can be used to determine the sector as shown in Table 2. Dynamic model of induction motor is implemented in Matlab to study the transient as well as steady state behavior of the drive system. Table 2 shows the determination the switching sector.

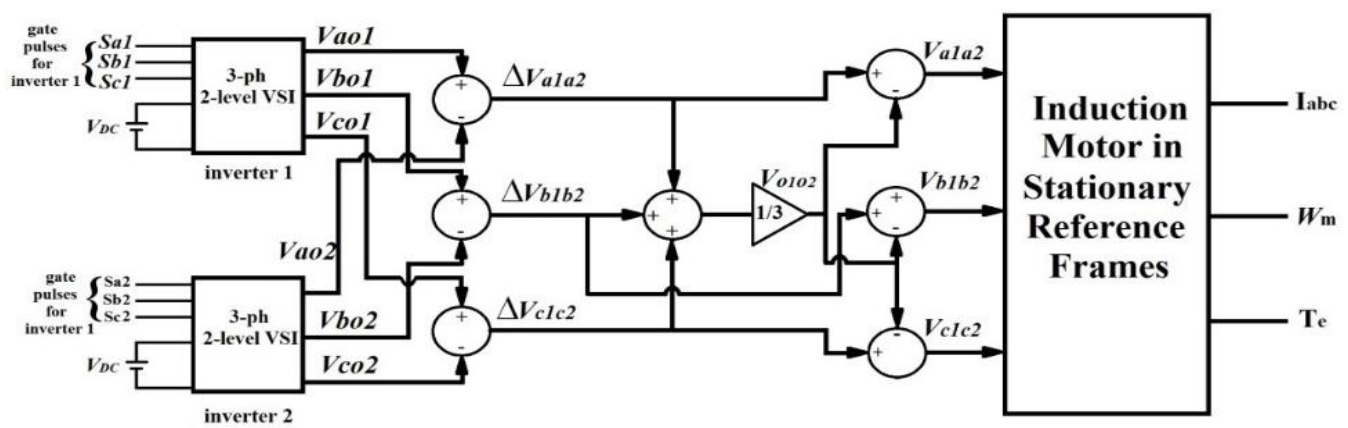

Figure 9. d-q model of an open-end winding induction motor

Table 2. Determination the Sectors

\begin{tabular}{cc}
\hline sector & degree \\
\hline 1 & $0<\Theta \leq 60$ \\
2 & $60<\Theta \leq 120$ \\
3 & $120<\Theta \leq 180$ \\
4 & $180<\Theta \leq 240$ \\
5 & $240<\Theta \leq 300$ \\
6 & $300<\Theta \leq 360$ \\
\hline
\end{tabular}




\section{RESULTS AND DISCUSSION}

The Matlab/ simulink of SVPWM is shown in Figures 10(a) and (b). As shown in Figure (10-a) and (10-b) the model was done by mixing MATLAB m-file and Simulink model. The output of the subsystem (duty) is the SVM signal Figure 6 which later will compare with triangular waveform to generate pulses as clear in the main model Figure10. The induction motor waveforms and the THD of input current will be as shown in Figure 11(a) and 11(b).

It can be cleared that the THDi=6.07\% which is a quite high value, it is unacceptable value. Therefore, it proposed to use dual two-level inverter based on SVPWM with a suitable connection as shown in Figure 12. The results of this model and THDi are shown in Figure 13(a), 13(b).

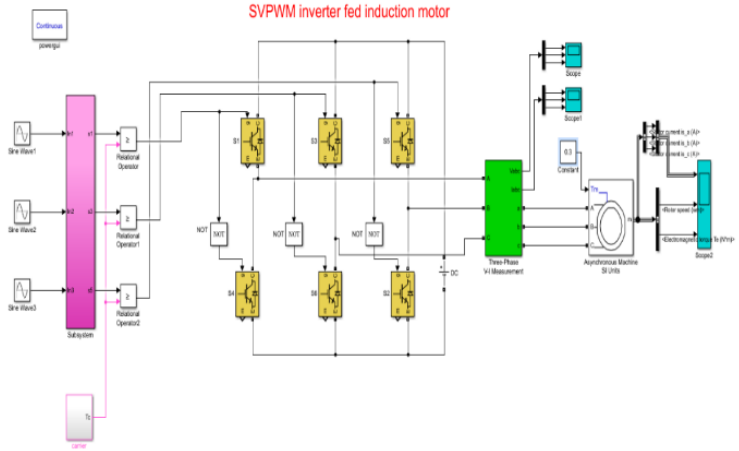

(a)

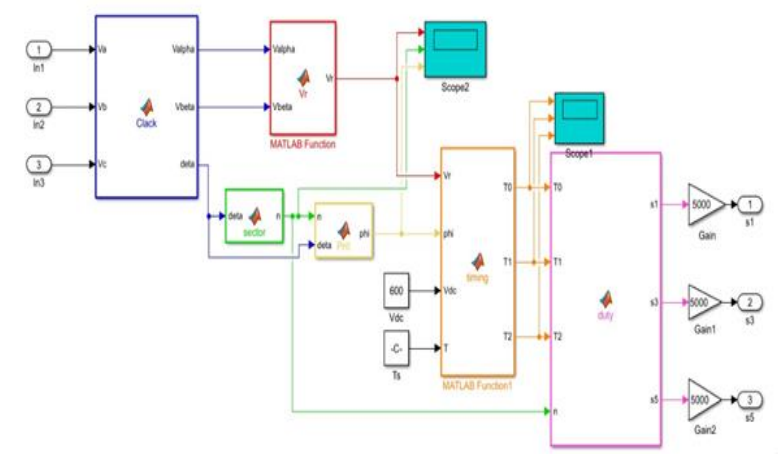

(b)

Figure 10. SVPWM Simulink, a) main model, b) subsystem

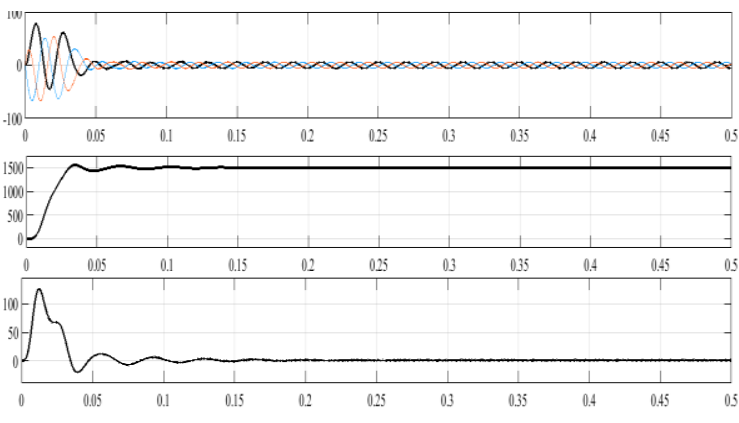

(a)

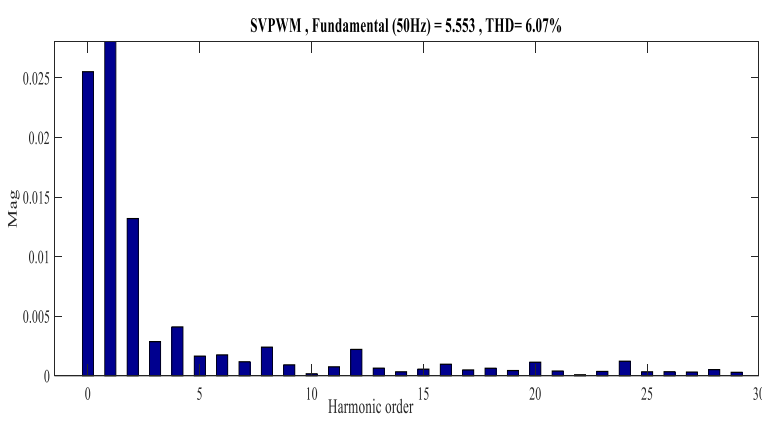

(b)

Figure 11. (a) Performance of induction motor, (b) (THD)i

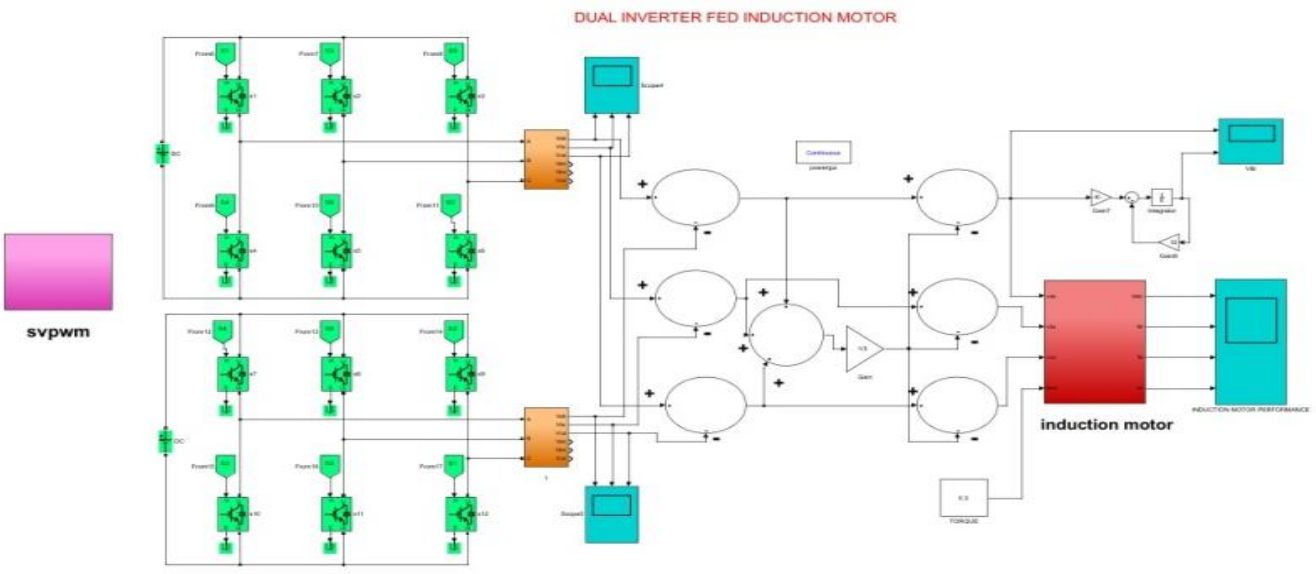

Figure 12. dual two-level inverter with SVPWM fed OEW induction motor Simulink 


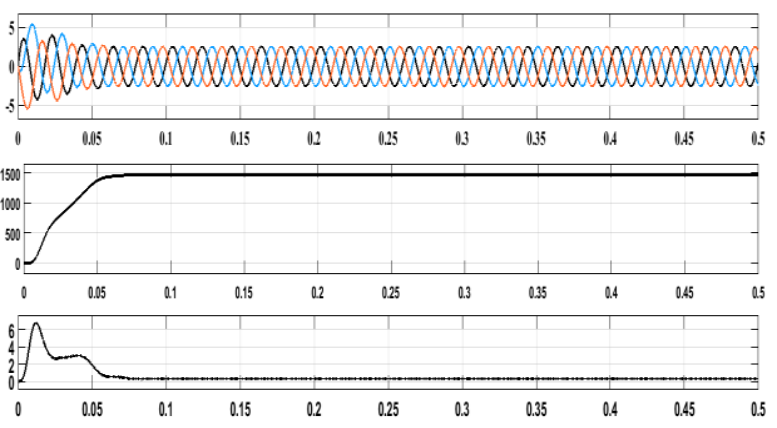

(a)

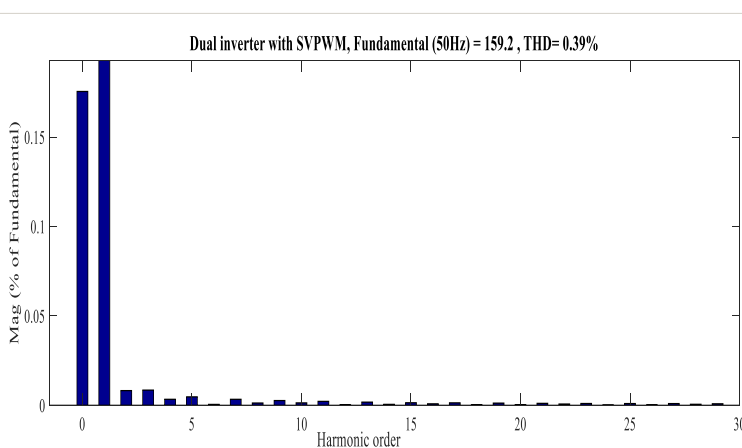

(b)

Figure 13. Simulation results of OEW induction motor, a) output performance, b) (THD)i

It can be observed from Figure 13 that the THDi $=0.39 \%$ and this is an acceptable value and gives a good performance with low distortion.

\section{CONCLUSION}

This paper utilizes space vector PWM to control the switching devices of the dual two-level inverter of the open-end winding induction motor. It concludes that the total harmonic distortion for the current signal has an appropriate value of $0.39 \%$. Therefore, the quality of the current signal is improved. In addition, the SVPWM reduces the controller execution time and also it saves the required memory capacity.

\section{REFERENCES}

[1] Hyun-Sam Jung, Chae-Eun Hwang, Hyeon-Sik Kim, Seung-Ki Sul, An Hee-Won, Hyunjae Yoo, "Minimum Torque Ripple Pulse Width Modulation With Reduced Switching Frequency for Medium-Voltage Motor Drive", Industry Applications IEEE Transactions on, vol. 54, no. 4, pp. 3315-3325, 2018.

[2] G. Salunkhe, A. M. Sapkal, "Reduction of Harmonics in Induction Motor Drive Using Harmonic Injection Method," IEEE International Conference on Recent Trends in Electronics, Information \& Communication Technology (RTEICT), 2016.

[3] M. Eltamaly, "Harmonic injection scheme for harmonic reduction of three-phase controlled converters". IET Power Electron, Vol. 11 Iss. 1, pp. 110-119, 2018.

[4] E. C. Standard 61000-3-2:2004: "Limits for harmonic current emissions", International Electromechanical Commission, Geneva, 2004.

[5] IEEE Std 519-2014: "IEEE recommended practices and requirements for harmonic control in electrical power systems”, IEEE-SA Standards Board, STD98587, 2014.

[6] J. Jeyashanthi, V. Hemamaheswari, G.LakshmiThilagam, and G. Loganayaki, “A Novel Approach for A Multirate 3 Level Carrier SVM of DTC Based IM Drive", International Conference on Recent Advancements in Electrical, Electronics and Control Engineering, 15-17 Dec. 2011.

[7] J. Faiz, and A. Ghasemi, "A new method for estimation of losses in inverter-fed induction machines including electrical insulation losses", IEEE International Power Electronics and Motion Control Conference (PEMC), pp.569-573, 2016.

[8] P. Sanjeev and S. Jain, "Analysis of conduction and switching losses in two level inverter for low power applications", Annual IEEE India Conference (INDICON), pp. 1-6, Dec. 2013.

[9] Kumar, K.V.P., Vinay, T.: "Predictive torque control of open-end winding induction motor drive fed with multilevel inversion using two two-level inverters", IET Electr. Power Appl, 12, (1), pp. 54-62, 2018.

[10] M. R. Baiju, K. K. Mohapatra, R. S. Kanchan, K. Gopakumar, "A Dual Two-Level Inverter Scheme With Common Mode Voltage Elimination for an Induction Motor Drive" Ieee Transactions on Power Electronics, 2004, VOL. 19, NO. 3, pp.794-805,2004.

[11] M. Sujatha, A.K. Parvathy "Improved reliable multilevel inverter for renewable energy systems". Indonesian Journal of Electrical Engineering and Computer Science (IJEECS), Vol. 14, No. 3, pp. 1141-1147, June 2019.

[12] M. Rasheed, R. Omar, M. Sulaiman , W. A. Halim.”A modified cascaded h-bridge multilevel inverter based on particle swarm optimisation (PSO) technique". Indonesian Journal of Electrical Engineering and Computer Science (IJEECS). Vol. 16, No. 1, pp. 41-51, October 2019.

[13] T-T. Nguyen." The multilevel inverter with clamped-diode". Indonesian Journal of Electrical Engineering and Computer Science (IJEECS). Vol. 14, No. 3, pp. 1189-1195, June 2019.

[14] Lega A. "Multilevel converters: dual two-level inverter scheme". PhD thesis, University of Bologna; Italy, 2007. 
[15] D.-H. Lee and J.-W. Ahn, “A simple and direct dead-time effect compensation scheme in pwm-vsi," IEEE Trans. Ind. Appl., vol. 50, no. 5, pp. 3017-3025, Sept 2014.

[16] Jena, S. P., \& Rout, K. C. "Comparative Analysis of Harmonic Reduction of VSI Fed Induction Motor Using SVPWM and Sinusoidal PWM". 2nd International Conference on Trends in Electronics and Informatics (ICOEI). 2018.

[17] Mishra, I., Singh, M., \& Roy, D. "Comparative Evaluation of Different Pulse Width Modulation Techniques on VSI Fed Three Phase Induction Motor". Recent Advances on Engineering, Technology and Computational Sciences (RAETCS). 2018.

[18] Huang, Yingliang, et al. "PWM Frequency Voltage Noise Cancellation in Three-Phase VSI Using the Novel SVPWM Strategy." IEEE Transactions on Power Electronics vol.31 PP.99 NO.6, June 2017.

[19] Phuong Hue Tran. "Matlab/simulink implementation and analysis of three pulse-width-modulation (PWM) techniques". Master of Science, Boise State University.2012.

[20] Bimal K.Bose, "Modern Power Electronics and AC Drives", PHI Learning Private Limited, New Delhi-110001, 2009.

[21] Wei Hu ; Heng Nian ; Dan Sun, "Zero-Sequence Current Suppression Strategy With Reduced Switching Frequency for Open-End Winding PMSM Drives With Common DC BUS”, IEEE Transactions on Industrial Electronics, Volume: 66 , Issue: 10 ,pp: 7613-7623, Oct. 2019.

[22] Zhiheng Lin ; Xinbo Ruan ; Lei Jia ; Wenxin Zhao ; Haitao Liu ; Peinan Rao,'Optimized Design of the Neutral Inductor and Filter Inductors in Three-Phase Four-Wire Inverter With Split DC-Link Capacitors", IEEE Transactions on Power Electronics, Volume: 34, Issue:1 ,pp: 247-262, Jan. 2019. 